\title{
Coronary artery bypass with ventricular restoration is superior to coronary artery bypass alone in patients with ischemic cardiomyopathy
}

Thomas S. Maxey, MD

T. Brett Reece, MD

Peter I. Ellman, MD

Paris D. Butler, BS

John A. Kern, MD

Curtis G. Tribble, MD

Irving L. Kron, MD
From the Departments of Thoracic and Cardiovascular Surgery, University of Virginia, Charlottesville, Va.

Read at the Twenty-ninth Annual Meeting of The Western Thoracic Surgical Association, Carlsbad, Calif, June 18-21, 2003.

Received for publication Feb 2, 2003; revisions requested Aug 24, 2003; revisions received Sept 9, 2003; accepted for publication Sept 30, 2003.

Address for reprints: Irving L. Kron, MD, Department of Surgery, Division of Thoracic and Cardiovascular Surgery, University of Virginia, Health Sciences Center, PO Box 801359, Charlottesville, VA 22908 (E-mail: ikron@ virginia.edu).

J Thorac Cardiovasc Surg 2004;127:428-34 $0022-5223 / \$ 30.00$

Copyright () 2004 by The American Association for Thoracic Surgery

doi:10.1016/j.jtcvs.2003.09.024
Background: Coronary artery bypass is an acceptable therapy in patients with ischemic cardiomyopathy. However, it has been demonstrated that patients with increased left ventricular volume have a worse outcome than patients with normal ventricular volume. Our hypothesis was that ventricular restoration plus coronary artery bypass provides improved outcome compared with coronary artery bypass alone in ischemic cardiomyopathy with ventricular enlargement.

Methods: A retrospective analysis was performed of patients with ischemic cardiomyopathy (ejection fraction $<30 \%$ ) who underwent operation between 1998 and 2002. Patients with enlarged ventricles (end-diastolic dimension $\geq 6.0 \mathrm{~cm}$ ) who underwent either coronary artery bypass alone or coronary artery bypass with ventricular restoration were compared. Preoperative and postoperative ejection fraction, morbidity, mortality, and freedom from heart failure (hospitalization secondary to heart failure) were assessed.

Results: Ninety-five patients were included in the study. Thirty-nine patients had coronary artery bypass alone, whereas 56 patients had ventricular restoration with coronary artery bypass. Both groups demonstrated an improved postoperative ejection fraction; however, the improvement was significantly greater in the ventricular restoration plus coronary artery bypass group $(P<.01)$. There were no hospital deaths in either group; however, late mortality was higher in the coronary artery bypass group. Freedom from heart failure was achieved in all but 2 of the ventricular restoration plus coronary artery bypass patients (2/56, or $3.6 \%)$ versus 7 in the coronary artery bypass group (7/39, or $18 \%)$. The combined outcomes of freedom from failure and late mortality were significantly improved in the ventricular restoration plus coronary artery bypass group $(P<.05)$.

Conclusions: Ventricular restoration affords significant improvement in ejection fraction compared with coronary artery bypass alone, without added mortality. Most importantly, left ventricular restoration reduces late morbidity and mortality compared with coronary artery bypass alone in patients with large ventricles.

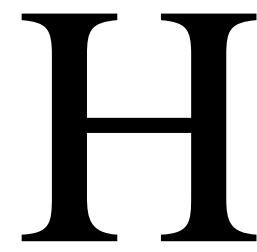

eart failure is one of the leading causes of hospitalization in the United States, with 400,000 to 700,000 new cases of heart failure diagnosed yearly. Most current therapeutic strategies are focused toward resolving the acute exacerbation of failure, resulting in a 3 -month re-admission rate of $20 \%$ to $50 \%$ and a devastating 2-year mortality of $35 \%$ to $50 \%{ }^{1,2}$ Each year, heart failure accounts for 1.5 million hospital admissions, with costs approximating $\$ 6000$ to $\$ 12,000$ per admission. ${ }^{2}$ 
Despite optimum medical therapy, some patients remain refractory to these strategies, and heart transplantation has become accepted therapy for some patients with severe heart failure. Not unlike any other form of transplantation, donor shortages and strict selection criteria limit the number of heart transplantations performed. The mortality associated with ischemic cardiomyopathy is related to the progressive loss of normal elliptical ventricular shape to that of a dilated ventricle with limited contractile and filling capacity. Although our group ${ }^{3}$ has demonstrated decreased mortality with revascularization in patients with poor left ventricular function, Yamaguchi and associates ${ }^{4}$ clearly demonstrated that overall mortality is related to preoperative left ventricular volume. Specifically, those patients with ischemic cardiomyopathy and left ventricular (LV) enlargement who underwent coronary artery bypass (CAB) did worse than those with small ventricles.

Dor and colleagues ${ }^{5}$ have demonstrated that ventricular restoration (VR) can be performed at the time of $\mathrm{CAB}$ with acceptable results. Athanasuleas and associates ${ }^{6}$ further validated Dor's institutional experience demonstrating the safety and efficacy of VR for dilated cardiomyopathy in a multicenter trial. We postulated that among patients with severely enlarged and ischemic LVs, improved outcome could be obtained with the addition of VR to CAB compared with $\mathrm{CAB}$ alone. This study compares the clinical outcomes of patients with severely depressed LV function who were treated either with $\mathrm{CAB}$ and VR or with $\mathrm{CAB}$ alone.

\section{Methods}

We retrospectively analyzed the medical records of all patients with ischemic cardiomyopathy who underwent $\mathrm{CAB}$ between 1998 and 2001 at the University of Virginia. Patients with dilated LVs (end-diastolic dimension $\geq 6.0 \mathrm{~cm}$ at the tips of the papillary muscles determined by transthoracic echocardiography) due to coronary artery disease were included in the study. Ninety-five patients met these criteria and were included in the study. Patients with dyskinetic ventricles (LV aneurysms) were excluded. The 95 patients were divided into 2 groups: coronary revascularization alone $(\mathrm{CAB} ; \mathrm{n}=39)$ and coronary revascularization with VR by using the Dor technique (CAB plus VR; $\mathrm{n}=56$ ). Preoperative ejection fraction $(\mathrm{EF})$, postoperative $\mathrm{EF}$, morbidity, mortality, and freedom from heart failure (defined as hospitalization secondary to heart failure) were assessed.

\section{Surgical Technique}

Transesophageal echocardiography was used to evaluate preoperative and postoperative LV and mitral valve function. Through a median sternotomy, the heart was exposed, and after adequate heparinization, the patient was placed on cardiopulmonary bypass. Myocardial protection was achieved with antegrade and retrograde blood cardioplegia.

After complete coronary revascularization (usually in the form of the internal thoracic artery to the left anterior descending artery and venous conduits to the remaining ischemic territories), the LV of the CAB plus VR group was entered. A 2-0 Prolene suture (Ethicon, Summerville, NJ) was placed around the circumference of the scar at the transition zone and tied down to restore the ventricular shape and volume. The location of this exclusion stitch (Fontan stitch) was determined before surgery by using echocardiography and ventriculograms to identify akinetic regions. Echocardiographic ventricular dimensions were obtained in both systole and diastole in the parasternal short axis view at the tips of the papillary muscles. An end-diastolic dimension $\geq 5.6 \mathrm{~cm}$ is consistent with American Society of Echocardiography criteria for a significantly enlarged ventricular volume. This study excluded patients with LV aneurysms (irregularity of LV shape) and therefore allowed a simplistic ventricular volume calculation based on the cross-sectional area and the length of the ventricle (volume = $5 / 6 A L$, where $A$ is the cross-sectional area of a short-axis view at the tips of the papillary muscles and $L$ is the long-axis view from the apex to the mitral annulus). ${ }^{7}$ Because patients with asymmetric or aneurysmal ventricles were excluded, the measured distance between the papillary muscles is indicative of global dilation of the LV. Echocardiography and ventriculograms allow a practical and repeatable measure to determine the ventricular dimension, as well as specific areas of akinesia, which are subsequently excluded. Typically we reduce the internal dimension of the ventricle to approximately 4 to $5 \mathrm{~cm}$ at the tips of the papillary muscles. A synthetic or pericardial patch was then secured over the ventricular opening with a running suture. The patch was carefully placed not only to reduce ventricular volume in the long axis, but also to restore elliptical shape to the dilated, often spherical, LV. Elliptical shape was achieved by placing the patch in an oblique plane to the mitral annulus. The edges of the ventricular free wall were then approximated by using mattress sutures and reinforced with running 3-0 Prolene. The patients were then weaned from cardiopulmonary bypass in standard fashion. Transesophageal echocardiography confirmed contractility, mitral valve function, and ventricular size. All patients recovered in the thoracic and cardiovascular postoperative unit and were discharged home on angiotensin-converting enzyme inhibitors per protocol unless this was contraindicated. Postoperative transthoracic echocardiographic data were obtained before discharge in most patients.

\section{Statistical Analysis}

Statistical analysis between the 2 groups was performed with a 2 -sample Student $t$ test. All $P$ values are 2 tailed. The results are presented as means $\pm \mathrm{SD}$.

\section{Results}

There were no significant preoperative differences between the 2 groups with regard to age, sex, New York Heart Association functional status, LV dimension, or EF (Table 1). There were, however, differences in urgency of operation and indication for operation; significantly more patients in the CAB plus VR group presented in cardiogenic shock. There was no significant difference in preoperative moderate to severe mitral regurgitation (MR) between groups (Table 2). There were no operative differences between the 2 groups with regard to reoperation, number of bypasses 
TABLE 1. Preoperative comparison data

\begin{tabular}{lcc}
\hline Variable & CAB $(\mathbf{n}=\mathbf{3 9})$ & $\mathbf{C A B}+\mathbf{V R}(\mathbf{n}=\mathbf{5 6})$ \\
\hline Age $(\mathrm{y})$ & $68.4 \pm 5.1$ & $63.1 \pm 6.2$ \\
Sex & $31 \mathrm{M}, 8 \mathrm{~F}$ & $42 \mathrm{M}, 14 \mathrm{~F}$ \\
Preoperative EF (\%) & $25.8 \pm 0.7$ & $22.1 \pm 1.1$ \\
LVedD (cm) & $6.4 \pm 0.3$ & $6.5 \pm 0.3$ \\
LVedV (mL) & $194 \pm 24$ & $201 \pm 21$ \\
NYHA class III-IV & 37 & 55 \\
Mitral regurgitation $\geq 2$ & 22 & 30
\end{tabular}

$C A B$, Coronary artery bypass; $V R$, ventricular restoration; $E F$, ejection fraction; $L V e d D$, left ventricular end-diastolic dimension; $L V e d V$, left ventricular end-diastolic volume; NYHA, New York Heart Association.

TABLE 2. Indications for operation

\begin{tabular}{lcc}
\hline Variable & CAB $(\mathbf{n}=\mathbf{3 9})$ & $\mathbf{C A B}+\mathbf{V R}(\mathbf{n}=\mathbf{5 6})$ \\
\hline Unstable angina alone & 22 & 20 \\
CHF alone & 8 & 14 \\
Angina and CHF & 9 & 16 \\
Shock* $^{*}$ & 0 & $6 \dagger$
\end{tabular}

$\overline{C A B}$, Coronary artery bypass; $V R$, ventricular restoration; $C H F$, congestive heart failure.

${ }^{*}$ Shock indicates hemodynamically lability necessitating emergency operation.

$\dagger P<.05$.

performed, ischemic time, or postoperative intra-aortic balloon pump use. Thirty-six patients required concomitant mitral valve repair (22 in the $\mathrm{CAB}$ group and 14 in the $\mathrm{CAB}$ plus VR group; Table 3). The senior author (I.L.K.) performed most of the operations in both the $\mathrm{CAB}$ and the CAB plus VR groups.

After surgery, both groups exhibited a significant improvement in LV function as determined by echocardiography; however, the degree of LV functional improvement was significantly higher in the CAB plus VR group $(33.43 \%$ $\pm 1.22 \%)$ than in the $\mathrm{CAB}$ group $(29.03 \% \pm 0.61 \% ; P<$ .01 ; Figure 1). Morbidity included atrial or ventricular arrhythmias (or both) in $8(20.5 \%)$ of $39 \mathrm{CAB}$ patients versus $14(25 \%)$ of $56 \mathrm{CAB}$ plus VR patients $(P=.78)$. There was no additional morbidity associated with these arrhythmias; however, $3 \mathrm{CAB}$ plus VR patients required defibrillator implantation, and 1 patient required ablation for persistent ventricular tachycardia. All 36 patients who underwent mitral valve repair (mean LV end-diastolic volume, $199 \pm 14$ $\mathrm{mL}$ ) had significant improvement in $\mathrm{LV}$ and valve function. With the exception of 1 patient (CAB plus VR), all patients had trace to no demonstrable postoperative MR. The 1 patient with persistent MR eventually went on to successful transplantation 11 months after surgery. Twelve-month freedom from heart failure was significantly improved in the CAB plus VR patients $(96.5 \%)$ compared with the CAB group $(82 \% ; P<.05)$. There were 2 moderate-term $(<12-$ month) failures in the $\mathrm{CAB}$ plus VR group. One of these

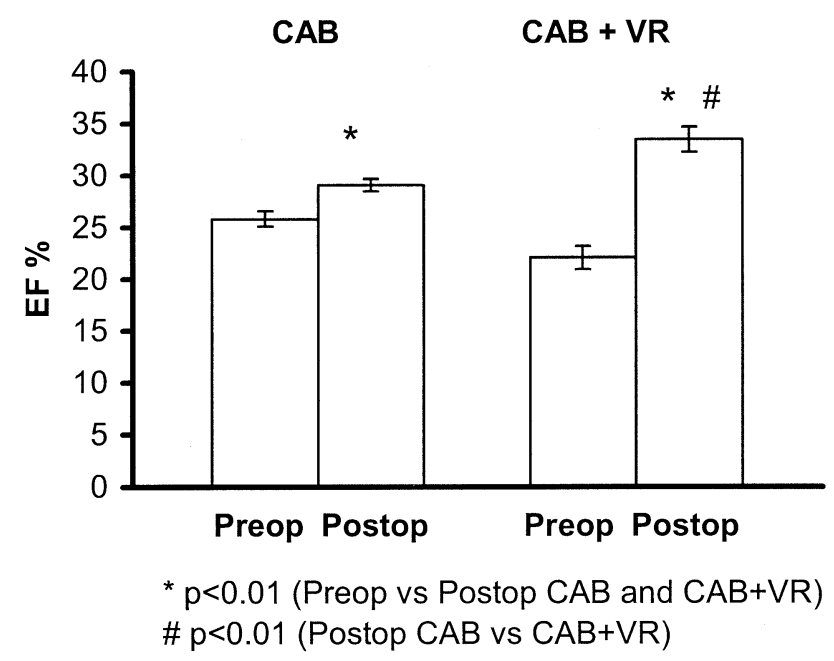

Figure 1. A comparison of the improvement in LV function between the CAB and CAB + VR groups.

TABLE 3. Operative comparison data

\begin{tabular}{lcc}
\hline Variable & CAB $(\mathbf{n}=\mathbf{3 9})$ & $\mathbf{C A B}+\mathbf{V R}(\mathbf{n}=\mathbf{5 6})$ \\
\hline Number of coronary grafts* & $3.4 \pm 0.8$ & $2.6 \pm 1.0$ \\
Mitral valve repair & 22 & 14 \\
Ischemic time (min) & $81 \pm 22$ & $90 \pm 28$ \\
CPB time (min) & $104 \pm 16$ & $135 \pm 28$ \\
Operative mortality & 0 & 0
\end{tabular}

$\overline{C A B}$, Coronary artery bypass; $V R$, ventricular restoration; $C P B$, cardiopulmonary bypass.

* Left internal thoracic artery to left anterior descending artery; venous conduits to other ischemic territories.

patients died 10 months later of renal failure, whereas the other (mentioned previously) went on to successful heart transplantation 11 months after VR. These patients did not undergo a mitral valve repair, yet moderate to severe MR developed in both in the months after the operation. There was no operative mortality for either group, yet late mortality (6-24 months) occurred in $2 \mathrm{CAB}$ patients (5.1\%). The $\mathrm{LV}$ end-diastolic volumes of these 2 patients were the largest in the CAB group (213 and $209 \mathrm{~mL}$ ). Both patients died of heart failure awaiting cardiac transplantation with severe MR (Table 4).

\section{Discussion}

The complex derangement of LV geometry caused by transmural infarct and/or aneurysm formation poses a number of problems for a surgeon. Ventricular reconstruction, as described by Vincent Dor, has demonstrated improved outcome in patients with ventricular aneurysms. ${ }^{5,8,9}$ Dor and others have also demonstrated that equivalent results could be achieved with VR even in patients without discrete ventricular aneurysms. ${ }^{6,9}$ Our group has demonstrated that 
patients with severely depressed LV function due to dilated cardiomyopathy (nonaneurysmal disease) can experience significant improvement by restoration of the elliptical shape of the LV.

It is well known that low $\mathrm{EF}(<20 \%)$ predicts higher mortality in patients with poor systolic function after $\mathrm{CAB}$. It has also become increasingly evident that ventricular volume is a strong predictor of outcome after myocardial infarction and reperfusion. ${ }^{4}$ The Global Utilization of Streptokinase and t-PA for Occluded Coronary Arteries data clearly demonstrate that large ventricular volume strongly predicts adverse outcomes, including early and late mortality. ${ }^{10}$

Investigators have suggested that patients with both ischemic cardiomyopathy and significant LV dilation should undergo transplantation secondary to poor outcome after CAB. ${ }^{11}$ However, is cardiac transplantation the best solution for ischemic cardiomyopathy with severely dilated and poorly functioning ventricles? Aziz and associates ${ }^{12}$ addressed this issue by comparing the outcomes of cardiac transplantation between patients with ischemic cardiomyopathy and those with idiopathic cardiomyopathy. Although the operative mortality between the 2 groups was essentially the same $(11.2 \%$ and $10.6 \%$, respectively), the 10 -year survival was remarkably different: $39 \%$ and $80 \%(P<.001)$ for ischemic and idiopathic cardiomyopathy, respectively.

The decision to operate on patients with severely depressed LV function is not straightforward. There is controversy regarding the lower limit in terms of acceptable preoperative $\mathrm{EF}$ in patients being considered for bypass surgery. Our group and others believe that EF provides some frame of reference to LV function, yet it does not dictate our operative management. ${ }^{13,14}$ Although low EF is an indicator of poor outcome, it is not in itself a contraindication to $\mathrm{CAB}$, nor does $\mathrm{EF}$ necessarily relate to ventricular volume, which is far more predictive of outcome. ${ }^{15,16}$ We cannot deny the aforementioned relationship between LV function, specifically EF, and postoperative morbidity and mortality. We, however, aim to reduce wall tension by reducing chamber size and favorably altering the oxygen supply-demand ratio of the remote muscle irrespective of the preoperative EF. Simply stated, we would not withhold operative therapy from a patient with ischemic cardiomyopathy and critical LV function.

Luciani and associates ${ }^{17}$ have suggested that preoperative angina may predict good outcome. Our experience has shown that although this may be true, the lack of angina did not predict a worse outcome. ${ }^{18}$ It is important to understand the distinct difference between a painful muscle that is ischemic and a dilated heart that, because of a change in fiber orientation, has impaired function independent of blood supply. In this study, the lack of angina did not significantly differ between the 2 groups (25\% CAB plus
TABLE 4. Postoperative comparisons

\begin{tabular}{lcc}
\hline Variable & CAB $(\mathbf{n}=\mathbf{3 9})$ & $\mathbf{C A B}+\mathbf{V R}(\mathbf{n}=\mathbf{5 6})$ \\
\hline Postoperative EF (\%) & $29 \pm 0.6$ & $33.4 \pm 1.2^{*}$ \\
Postoperative LVedD & $5.8 \pm 1.0$ & $4.3 \pm 0.3^{*}$ \\
Postoperative LVedV (mL) & $174 \pm 39$ & $119 \pm 35^{*}$ \\
Operative mortality & 0 & 0 \\
Hospital stay (d) & $6.9 \pm 1.9$ & $7.9 \pm 2.0$ \\
Recurrent heart failure & $7 / 39(18 \%)$ & $2 / 56(4 \%)^{*}$ \\
Long-term mortality & $5.1 \%$ & $1.8 \% \%^{*} \dagger$
\end{tabular}

$C A B$, Coronary artery bypass; $V R$, ventricular restoration; $E F$, ejection fraction; $L V e d D$, left ventricular end-diastolic dimension; $L V e d V$, left ventricular end-diastolic volume.

${ }^{*} P<.05$.

†Although recurrent heart failure was the end point for this analysis $(\mathrm{n}=$ 2 in the CAB + VR group), mortality is reported for interest. One patient had successful heart transplantation.

VR vs $21 \% \mathrm{CAB}$ ) and was not an independent predictor of survival or heart failure.

Progressive ventricular dilation often distorts critical elements of the mitral apparatus and can result in functional MR. Therapy for functional MR should be aimed at restoring the normal relationships of the mitral apparatus that have been distorted by LV remodeling. In patients with dilated cardiomyopathy and functional MR who are undergoing VR, surgical therapy should address all components of the mitral apparatus. We completely revascularize all viable myocardium, restore ventricular volume and shape, decrease orifice area, and realign the papillary muscles. Di Donato and colleagues ${ }^{19}$ have convincingly demonstrated that late MR after the Dor procedure is associated with poor prognosis and emphasized early (intraoperative) correction. Our group and others have demonstrated that relationships of the mitral apparatus occasionally can be restored by reducing the area between the widened papillary muscles with sutures. ${ }^{20,21}$ Menicanti and colleagues ${ }^{22}$ have described the technique of narrowing the interspace between the papillary muscles by imbricating sutures while simultaneously addressing revascularization and restoring ventricular shape. We do not routinely use this technique; however, the basic tenet of restoring all components of the mitral apparatus toward normalcy is clear.

There is little doubt that mitral repair or replacement should be performed concomitantly with VR when significant MR exists; however, it is not established which technique is most effective. ${ }^{15}$ In patients who require annuloplasty beyond the limits obtained by the Dor procedure, we routinely use a mitral annuloplasty ring through the atrial approach and a chordae-shortening technique of suturing the posterior papillary muscle and chordae to the posterior ventricular wall to allow proper coaptation of the leaflets. ${ }^{21}$ This study included 36 patients who required mitral valve repair (22 CAB and $14 \mathrm{CAB}$ plus VR). Although there were more patients in the $\mathrm{CAB}$ group with MR, we can draw no 
hard conclusions that this observation accounts for differences in outcome between the 2 groups. The clinical effect of restoring elliptical ventricular shape and re-establishing normalcy to the mitral apparatus cannot be ignored.

We reviewed mitral valve function after VR in an earlier series of patients who underwent VR at our institution. ${ }^{16}$ Improvement in functional MR was observed in $64 \%$ of patients despite no mitral intervention. This amelioration of mitral insufficiency after the Dor procedure is related to the reshaped ventricle as described by Buckberg and Athanasuleas. ${ }^{23}$ Restoration of the LV geometry results in a narrower configuration of papillary muscles, with an improvement in the degree of mitral insufficiency. However, the long-term effects of this reshaped geometry and the realignment of the mitral apparatus need to be elucidated.

The relationship between improvement in LV performance and symptomatic improvement is not clear. ${ }^{24} \mathrm{Al}-$ though improvements in LV function after VR may not always be profound, most patients still experience symptomatic improvement. Luciani and associates ${ }^{25}$ demonstrated that despite improved $\mathrm{EF}$, late functional outcome after $\mathrm{CAB}$ in patients with ischemic dilated cardiomyopathy remains suboptimal with recurrent congestive heart failure. This observation, as well as our own data, demonstrates that a reduction in ventricular volume is a central feature of improvement. We noted symptomatic improvement in all but 1 patient (CAB plus VR) regardless of postoperative objective EF changes.

When the extent of myocardial exclusion is determined, the morphology of the lesion must be appreciated, and areas of akinesia or dyskinesia must be recognized. With increased use of thrombolysis and angioplasty, the classic appearance of a thin, scarred myocardium that collapses with ventricular venting may not be evident. In fact, the epicardium often appears normal, with somewhat thickened muscle in the anterior apical segment. It is crucial to be able to look beyond the normal-appearing epicardium and exclude the entire segment to delete the midmyocardial and endocardial scar. There is no doubt that highly sophisticated volumetric studies, specifically with cardiac magnetic resonance, will help to distinguish subtle differences in LV wall alterations, as well as accurately quantify preoperative and postoperative ventricular volumes. To date, we have not used this modality at our institution for VR data; however, it may be used in future studies. We typically rely on preoperative transthoracic echocardiography that is closely cross-referenced with left ventriculogram information. Some authors prefer the beating-heart digital palpation technique to distinguish the border zone between healthy and damaged myocardium. ${ }^{26}$ Our group, however, has recently demonstrated that the beating-heart technique provides no additional benefit compared with preoperative determination of myocardial exclusion. ${ }^{27}$
The primary goal of this project was to review our institutional experience with surgical treatment of dilated cardiomyopathy. The study was retrospective and compared a surgical technique $(\mathrm{CAB})$ used primarily in the earlier part of this experience with one (CAB plus VR) used mostly in the latter half of the study. Whereas echocardiography and ventriculograms were performed in most patients before surgery, ventriculography was not routinely used in the postoperative period. Follow-up EFs and ventricular volumes were mostly assessed by transthoracic echocardiography in ambulatory patients; however, these data were not obtained at precisely the same postoperative intervals (range, 7-35 days after surgery). Mitral annular size and papillary muscle width were not measured in all patients.

Some patients have reversible ischemic LV dysfunction that improves after coronary revascularization. Although myocardial viability was not quantified before surgery in every patient, the effect of myocardial hibernation is minimized in the early postoperative period, when we reported the LV functional improvement.

\section{Conclusions}

Although this study is retrospective and observational and is subject to inherent bias, it does begin to answer how to treat the patient with a large ventricle and ischemic cardiomyopathy. Yamaguchi and associates ${ }^{4}$ and White and colleagues ${ }^{28}$ have clearly demonstrated the grave prognosis of patients with large ventricular volumes. We have demonstrated excellent short-term results with $\mathrm{CAB}$ alone but inferior mid-term results compared with $\mathrm{CAB}$ plus VR. The National Institutes of Health-funded Surgical Treatments for IsChemic Heart failure trial has been designed to provide more information on this challenging group of patients.

\section{References}

1. Mills RM Jr, Young JB, editors. Practical approaches to the treatment of heart failure. Philadelphia: Williams \& Wilkins; 1998. p. 2.

2. Carson PE. Beta blocker treatment in heart failure. Prog Cardiovasc Dis. 1999;41(4):301-21.

3. Kron IL, Flanagan TL, Blackbourne LH, et al. Coronary revascularization rather than cardiac transplantation for chronic ischemic cardiomyopathy. Ann Surg. 1989;210:348-52.

4. Yamaguchi A, Ino T, Adachi H, Murata S, Kamio H, Okada M, et al. Left ventricular volume predicts postoperative course in patients with ischemic cardiomyopathy. Ann Thorac Surg. 1998;65:434-8.

5. Dor V, Saab M, Coste P, et al. Left ventricular aneurysm: a new surgical approach. Thorac Cardiovasc Surg. 1989;37:11-9.

6. Athanasuleas CL, Stanley WH, Buckberg GD, Dor V, DiDonato M, Blackstone EH. Surgical anterior ventricular endocardial restoration (SAVER) in the dilated remodeled ventricle after anterior myocardial infarction. J Am Coll Cardiol. 2001;37:1199-1209.

7. Feigenbaum H. Echocardiography. 5th ed. Philadelphia: Lippincott Williams \& Wilkins; 1994.

8. DiDonato M, Sabatier M, Montiglio F, et al. Outcome of left ventricular aneurysmectomy with patch repair in patients with severely depressed pump fraction. Am J Cardiol. 1995;76:557-61.

9. Dor V. Surgery of left ventricular aneurysm. Curr Opin Cardiol. 1990;5:773-80.

10. Migrino RQ, Young JB, Ellis SG, White HD, et al. End-systolic 
volume index at 90 to 180 minutes into reperfusion therapy for acute myocardial infarction is a strong predictor of early and late mortality. The Global Utilization of Streptokinase and t-PA for Occluded Coronary Arteries (GUSTO)-I Angiographic Investigators. Circulation. 1997;96:116-21.

11. Bolling SF, Smolens IA, Pagani FD. Surgical alternatives to heart failure. J Heart Lung Transplant. 2001;20:729-33.

12. Aziz T, Bugess M, Rahman AN, et al. Cardiac transplantation for cardiomyopathy and ischemic heart disease: differences in outcome up to 10 years. J Heart Lung Transplant. 2001;20:525-33.

13. Micklebourough LL, Maruyama H, Takagi Y, et al. Results of revascularization in patients with severe left ventricular dysfunction. Circulation. 1995;92(9 suppl):II73-9.

14. Elefteriades JA, Tellides G, Samady H, Yepremyan M, Darr U, Wackers FJ, et al. Coronary artery bypass for advanced left ventricular dysfunction. In: Masters RG, editor. Surgical options for the treatment of heart failure. Dordrecht: Kluwer Academic; 1999. p. 15-31.

15. Di Donato M, Sabatier M, Dor V, Gensini GF, Toso A, Maioli M, et al. Effects of Dor procedure on left ventricular dimension and shape and geometric correlates of mitral regurgitation one year after surgery. J Thorac Cardiovasc Surg. 2001;121:91-6.

16. Kaza AK, Patel MR, Fiser SM, Long SM, Kern JA, Tribble CG, et al. Ventricular reconstruction results in improved left ventricular function and amelioration of mitral insufficiency. Ann Surg. 2002;235:828-32.

17. Luciani GB, Faggian G, Razzolini R, Livi U, Bortolotti U, Mazzucco A. Severe ischemic left ventricular failure: coronary operation or heart transplantation. Ann Thorac Surg. 1993;55:719-23.

18. Kron IL, Flanagan TL, Blackbourne LH, Schroeder RA, Nolan SP. Coronary revascularization rather than cardiac transplantation for chronic ischemic cardiomyopathy. Ann Surg. 1989;210:348-54.

19. Di Donato M, Sabatier M, Dor V, et al. Akinetic versus dyskinetic postinfarction scar: relation to surgical outcome in patients submitted to endoventricular circular patch plasty repair. J Am Coll Cardiol. 1997;29:1569-75.

20. Liel-Cohen N, Guerrero JL, Otsuji Y, et al. Design of a new surgical approach for ventricular remodeling to relieve ischemic mitral regurgitation: insights from 3-dimensional echocardiography. Circulation. 2000;101:2756-63.

21. Kron IL, Green GR, Cope JT. Surgical relocation of the posterior papillary muscle in chronic ischemic mitral regurgitation. Ann Thorac Surg. 2002;74:600-1.

22. Menicanti L, Di Donato M, Frigiola A, Buckberg G, et al. Ischemic mitral regurgitation: intraventricular papillary muscle imbrication without mitral ring during left ventricular restoration. J Thorac Cardiovasc Surg. 2002;123:1041-50.

23. Buckberg GD, Athanasuleas CL. Seeing congestive heart failure with the eyes of the mind: a surgical view. Semin Thorac Cardiovasc Surg. 2001;13:431-4.

24. Froehlich RT, Falsetti HL, Doty DB, Marcus ML. Prospective study of surgery for left ventricular aneurysm. Am J Cardiol. 1980;45:923-31.

25. Luciani GB, Montalbano G, Casali G, Mazzucco A. Predicting longterm functional results after myocardial revascularization in ischemic cardiomyopathy. J Thorac Cardiovasc Surg. 2000;120:478-89.

26. Athanasuleas CL, Stanley AW Jr, Buckberg GD. Restoration of contractile function in the enlarged left ventricle by exclusion of enlarged akinetic anterior segment: surgical strategy, myocardial protection, and angiographic results. J Card Surg. 1998;13:418-28.

27. Maxey TS, Reece TB, Ellman PI, Kern JA, Tribble CG, Kron IL. The beating heart approach is not necessary for the Dor procedure. Ann Thorac Surg. 2003;76:1571-5.

28. White HD, Norris RM, Brown MA, et al. Left ventricular end-systolic volume as the major determinant of survival after recovery from myocardial infarction. Circulation. 1987;76:44-51.

\section{Discussion}

Dr Andrew S. Wechsler (Philadelphia, $\mathrm{Pa}$ ). [This discussion was prepared by Dr Wechsler but was presented by the moderator in his stead.] Dr Maxey and his colleagues from rural Virginia are to be commended for outstanding results in a challenging cohort of patients. More specifically, there were 2 cohorts of patients, and the task of the reader or listener is to discern whether or not there is enough evidence presented to make one believe that 1 treatment strategy was better than the other. To aid in that task, I have several questions. (1) In providing the data for "recurrent heart failure," were the measurements made after the same number of months? The coronary bypass-alone group was followed up longer than the $\mathrm{CAB}$ plus ventricular restoration group. Are early, 6-month, and later data available? (2) How long after operation did mortality in the 2 groups occur? Would it have been better to plot freedom from death versus time?

I'll let you respond to those, and then he has a couple of others.

Dr Maxey. Thank you very much. Certainly these are very valid questions for this type of study. As far as the time period from recurrent heart failure, due to the span of the study, some of the patients that were in the $\mathrm{CAB}$-alone group were in the earlier parts of the study. We have continued to adopt a more liberal approach to ventricular remodeling techniques. Regarding the patients that died that you were questioning in the ventricular reconstruction group: 1 patient received a successful transplant at 10 months, and 1 patient died at 11 months. The deaths in the CAB-alone group spanned from a 4-month period to a 16-month period, and I do not have the specifics of the individual death time points there.

MODERATOR. Question number 3. I'm surprised by the greatly reduced use of mitral valve repair in the CAB plus ventricular restoration group. If one did logistic regression analysis, I suspect that the mitral valve repair would be associated with worse outcome and greater postoperative dimensions. This represents how statistics that prove association rather than causality can be confusing. Unfortunately, it also raises the inherent difficulties in assessing treatment outcomes in nonrandomized studies.

Another question: are data available for the presence or absence of mitral valve leakage in each group at the time of follow-up?

Dr Maxey. That is correct. Both groups of patients received noninotropic supported transthoracic echocardiography in the postoperative period. At that time, mitral valve competence was analyzed.

MODERATOR. And the final question: In the manuscript, the authors mentioned their technique of shortening cords to decrease mitral regurgitation by moving the posterior papillary muscle closer to the ventricular wall. In my experience, the mitral leakage is almost always due to tethering of the posterior leaflet. Is it possible that the maneuver described functionally lengthens the chordae, allowing greater posterior leaflet mobility?

Dr Maxey. Yes. I think that is correct. We have previously published our results with this technique. We use it concomitantly with a semirigid ring, specifically in Carpentier IIIb disease, with a fair amount of success, and we have published that data.

Dr Robert Robbins (Stanford, Calif). I know we are behind, but I just wanted-I was telling Irv there is an interesting paper from a group in the Netherlands-the senior author is Jerome Bachs(?)—-that asks why patients with hibernating myocardium do not get better after $\mathrm{CAB}$, and his answer was because the ones that have the large ventricular volumes don't get better. My question is, do you have any data on whether hibernating myocardium played 
a role in your results? For instance, if the patients with the $\mathrm{CAB}+$ VR had more hibernating myocardium than the others, you would expect that this group of patients would have done better.

And just 1 quick comment about the volume. I think most people would say now that magnetic resonance imaging is a better way to get volume, so you might want to just say something about that.

Dr Maxey. Certainly. I'll answer your last question first if I may. This was a preliminary study. The echocardiographic evidence that we used, as I mentioned, was very simple. I think that in the future, as this program progresses, certainly there is a role for cardiac magnetic resonance or better imaging techniques to evaluate ventricular volumes.

I am familiar with the study that you mentioned regarding hibernation. I don't think that that had an effect in our particular patient population, because our LV function data were recorded just prior to discharge-in other words, early on in these patients' postoperative course. To further define the role of hibernating myocardium, we will need to reevaluate all study patients' LV function further out in their postoperative course.

\section{Authoritative}

The Journal of Thoracic and Cardiovascular Surgery is the most frequently cited thoracic/cardiovascular surgery journal in the Science Citation Index. An article in JTCVS is cited on average almost twice as

often as those in the closest cardiothoracic journal. 